\title{
Detection of Insulin-Like Growth Factor 1 Based on an Electrochemical Impedance Spectroscopy Sensor
}

\author{
Lin Ding ${ }^{1}$, Hongtao Zhang ${ }^{2, *}$ \\ ${ }^{1}$ Department of Clinical Skills Experimental Teaching Center, Wuchang Hospital, Qiqihaer City, \\ Heilongjiang Province, 161000, P.R. China \\ ${ }^{2}$ Department of Obstetrics and Gynecology, Third Affiliated Hospital, Qiqihar Medical University, \\ No.27, Tai Shun Street, Tiefeng District, Qiqihar City, Heilongjiang Province, 161000, P.R. China \\ *E-mail: hongtaozhang@126.com
}

doi: $10.20964 / 2017.12 .37$

Received: 3 September 2017 / Accepted: 24 October 2017 / Published: 12 November 2017

This work presents the fabrication of a novel label-free electrochemical sensor towards the determination of insulin-like growth factor 1 (IGF-1) by immobilizing IGF-1 monoclonal antibodies using multiwalled carbon nanotubes (MWCNTs) and an ionic liquid (IL). It was found that the increased impedance values were linearly related with the logarithm of the IGF-1 concentrations $(0.4$ $15 \mathrm{ng} / \mathrm{mL}$ ). Furthermore, based on a signal-to-noise ratio of 3 , the limit of detection (LOD) was calculated to be $22 \mathrm{pg} / \mathrm{mL}$. The results showed that our developed sensor is highly stable, sensitive, and simple to use, showing potential for the early diagnosis of polycystic ovary syndrome.

Keywords: Insulin-like growth factor 1; Polycystic ovary syndrome; Multi-walled carbon nanotube; Electrochemical sensor; Ionic liquid

\section{FULL TEXT}

(C) 2017 The Authors. Published by ESG (www.electrochemsci.org). This article is an open access article distributed under the terms and conditions of the Creative Commons Attribution license (http://creativecommons.org/licenses/by/4.0/). 